\title{
Tropical Sprue
}

\author{
V.I. Mathan \\ The Wellcome Research Unit and Department of Gastroenterology, Christian Medical College \\ Hospital, Vellore 632 004, India
}

\section{Introduction}

Tropical sprue is a primary malabsorption syndrome affecting residents of and visitors to several tropical regions $[15,27]$. Patients usually present with a history of chronic diarrhoea and on investigation are found to have malabsorption of a variety of nutrients and consequent multiple nutritional deficiencies. The aetiology of tropical sprue is not known, but the basic lesion is persistent damage to enterocytes, probably in the stem cell compartment [26]. The enterocytes and colonocytes are a single layer of epithelial cells, separating the external environment in the lumen of the gastrointestinal tract from the internal environment of the body. They act as the first pass organ for a variety of substances, nutrients, drugs, ingested toxins etc., and are in intimate contact with the luminal contents of the gastrointestinal tract, especially unabsorbed food residue and the resident microbial flora $[6,7,13,34]$. The enterocytes turn over rapidly with a short half life. The intestinal mucosa also has a large population of immunocytes, as well as cells specialised in antigen sampling, the ' $M$ ' cells [43]. The complex organization of this primary barrier suggests that a variety of factors may compromise its integrity. The diet and the flora of the intestinal lumen in tropical residents are different compared to residents of temperate zones and there are several gastrointestinal diseases, including tropical sprue, which are more prevalent in tropical climates [28]. Are there any identifiable structural or functional differences between the gastrointestinal mucosa of healthy residents of tropical and temperate regions?

\section{The Intestinal Mucosa of Asymptomatic Tropical Residents}

A variety of minor, morphological abnormalities, which would be consistent with a diagnosis of gastrointestinal illness in temperate climate residents, were present in jejunal mucosal biopsies from apparently healthy, asymptomatic volunteers from tropical countries [4]. Increase in the thickness of the crypt (stem cell) layer 
with accelerated cell turnover, an increase in epithelial lymphocytes and lamina propria mononuclear cells and enterocyte abnormalities on ultrastructural examination characterised these morphological alterations [24]. The changes were not confined to the small intestine, ultrastructural abnormalities being present also in colonocytes [23]. Intestinal absorption tests in a stratified random sample of the rural population in southern India showed that up to $40 \%$ of asymptomatic adults had D-xylose malabsorption, $10 \%$ mild steatorrhoea ad about $3 \%$ vitamin $B_{12}$ malabsorption [3]. The faecal wet weight was high and there was an increased loss of nutrient energy and nitrogen in the faeces [8]. This combination of morphological and functional alterations in the intestine of apparently healthy residents of several tropical regions has been termed "Tropical enteropathy" [3].

Tropical enteropathy is widely prevalent in many tropical countries and appears to be related to poorer socioeconomic status and widespread environmental contamination. Expatriates from temperate climates to tropics developed this change in about 3 months of residence and the pattern reverted to the temperate zone "normal" about 1 year after return [20]. Residents of tropical countries who migrate to temperate zone countries gradually assume the temperate zone mucosal pattern over a period of 3 to 5 years [21]. The foetal intestine in southern India is morphologically identical to that in temperate climates and the changes of tropical enteropathy only appear within 2-12 weeks of birth [11]. In animal experiments, it has been shown that contact with luminal contents is essential for the development of the lesion and that isolation of loops of bowel in Thiry-Vella fistulae prevent or revert the changes [10]. The morphological changes involved not only the epithelium but also structural changes in the lamina propria, including immunocytes [37, 39]. Tropical enteropathy, therefore, is an adaptive change of the intestinal mucosa to a variety of luminal factors and is the background on which gut pathology develops in residents of many tropical countries [36].

\section{Epidemiology and Clinical Features of Tropical Sprue}

The geographical distribution of tropical sprue is as yet unexplained. It has been described in most of south and south-east Asia, Central America and the Caribbean islands but not in Jamaica or sub-Saharan Africa [27, 32]. In the Indian subcontinent, tropical sprue is endemic (sporadic cases) and occurs also in well-defined epidemics [1, 30, 31]. A detailed study of several epidemics in southern India suggested an infectious aetiology, but as yet no causal bacteria, virus or parasite has been identified [29, 33].

Clinically the patients present with chronic diarrhoea, anaemia, wasting, glossitis and evidence of hypoproteinaemia [2]. There is also evidence of damage to the colon [38]. A few patients may present with only the nutritional sequelae of malabsorption, especially megaloblastic anaemia. Both adults and children are affected, although the latter appear to be less susceptible [31]. In the marginally nourished population of rural southern India, where access to medical facilities is limited, the epidemics were associated with a high mortality, although with symptomatic therapy for control of diarrhoea, correction of dehydration and nutritional supplementation, spontaneous remissions are possible. In southern India, 
therapy with antibiotics on folic acid did not appear to be curative [2], in contrast to results of such therapy in patients in the Caribbean or in expatriates from the temperate zones $[14,17]$. These differences in the response to therapy in addition to epidemiological and clinical differences suggested that tropical sprue is a "syndrome' of possibly multiple aetiology in which damage to enterocytes manifests as chronic diarrhoea and malabsorption [27].

\section{Pathophysiology of Tropical Sprue}

The malabsorption of nutrients and diarrhoea characteristic of the disease points to a primary lesion in the absorptive cells, the enterocytes. In the jejunal mucosa of patients with tropical sprue, the height of villi are reduced with an increase in the thickness of crypts, an appearance described as partial villus atrophy [9, $12,26,41]$. In addition to this overal alteration in the architecture, even at light microscopic examination damage to enterocytes can be clearly identified with altered glycocalyx, cuboidal and flattened enterocytes and a marked increase in the infiltration of the epithelium by lymphocytes. The architectural alterations and enterocytes changes are seldom as severe as found in gluten-sensitive enteropathy. In southern India, in over 2000 patients with tropical sprue a flat jejunal mucosal architecture has never been encountered.

Shortening and sparsity of the microvilli, damage to surface membrane, reduction in glycocalyx, increase in lysosomal bodies and damage to rough endoplasmic reticulum and mitochondria are characteristic of the enterocyte damage at the ultrastructural level [24]. The dmage is not confined to the surface enterocytes but is prsent also in the crypt cells and the stem cells from which enterocytes are renewed. This lesion in the stem cell compartment has been found as early as $48 \mathrm{~h}$ from the onset of diarrhoea in patients affected in epidemics of tropical sprue. Extrusion of the damaged enterocytes from the epithelial layer occurs at all levels, crypt and villus, in contrast to the normal situation where senescent enterocytes are extruded only from the zone of extrusion at the tips of villi.

In vitro organ culture of jejunal mucosal biopsies for up to $48 \mathrm{~h}$, with pulse labelling with $\left[{ }^{3} \mathrm{H}\right]$ thymidine, showed an increase of cells in the $S$ phase and a more rapid migration to, and loss from, the villi of labelled cells [26]. Mitotic counts were also increased indicating a more rapid turnover of enterocytes. It was not possible to differentiate between turnover of different populations of stem cells, damaged or apparently normal, in these studies. These changes may be due to the primary agent responsible for tropical sprue in southern India itself altering the cell turnover. The lesion responsible for this may be morphologically occult in the stem cell compartment and may manifest only in the villi. Alternatively, the increased cell turnover may only be a response to the loss of damaged cells from the functional compartment, the villi.

The nature of the agent that leads to enterocyte damage is not known. In southern India the only lead that has been obtained in detailed studies of several epidemics of tropical sprue was the association between patients affected in an epidemic and the prevalence of fringed pleomorphic virus-like particles in stool samples [25]. Several patients with chronic tropical sprue were found to excrete 
these particles for months and electron microscopic examination of their jejunal biopsies provided evidence suggestive of infection by these particles [5]. To date it has not been possible to grow these particles in vitro and there is still considerable doubt as to their exact significance.

In contrast to the results from southern India, crypt enterocyte damage has not been reported from other regions. At least in Puerto Rico there appears to be a relationship between the colonization of the small intestine by toxin-producing coliforms and the diarrhoea and malabsorption in tropical sprue [16, 18]. These patients also respond dramatically to therapy with broad spectrum antibiotics $[19$, 40]. The small bowel flora in patients in southern India was within the normal limits [6]. These regional differences further support the hypothesis that tropical sprue is a syndrome of possibly multiple aetiopathogenesis.

\section{Immunopathology of Tropical Sprue}

Any study of immunological alteration in tropical sprue has to take into account the role of the intestinal tract as an immunological organ; a primary barrier to the external environment, with a large population of immunocytes and antigen sampling cells. Both serum- and cell-mediated changes in immune parameters should ideally be evaluated in enteric diseases but the difficulties of adequate sampling of gut mucosa and the necessity for including appropriate controls have been limiting factors. Many of the earlier reports of serum immunoglobulin changes in tropical sprue were on a limited number of patients, for a few parameters and, when controls were studied, they included only healthy controls. The results obtained were not sufficient to decide whether immunological changes were primary events in the pathogenesis or were secondary to structural or functional changes in the intestine. Appropriate controls for a group of tropical sprue patients should include two groups, healthy asymptomatic individuals and patients with other gastrointestinal illnesses with no malabsorption. While both the control groups would have tropical enteropathy, the latter group may also indicate immunological changes which are primarily related to altered gut structure or function without malabsorption.

A detailed study of 85 patients with both endemic and epidemic tropical sprue, 150 consecutive patients with gastrointestinal illnesses other than tropical sprue and a group of 57 healthy volunteers was carried out in southern India [39]. Serum immunoglobulins, functional antibodies to enterobacterial common antigens and rotavirus, autoantibodies, complement, orosomucoid, peripheral blood lymphocyte estimation and blast transformation were tested. Intraepithelial lymphocytes were quantitated and the presence of functional secreted antibodies tested in jejunal luminal fluid. Serum concentration of $\mathrm{IgG}, \operatorname{IgE}$, complement $\mathrm{C}_{4}$ and orosomucoid were significantly different, the prevalence of gastric parietal cell antibodies was significantly higher and peripheral blood lymphopaenia was present, in patients with tropical sprue. While all these differences were significant when compared to the group of normal volunteers, none of these were significantly different from the group of control subjects with gastrointestinal illnesses without malabsorption. The parameters were also not significantly different between the 
two groups of controls. This suggested that abnormalities in the integrity of the gastrointestinal barrier can give rise to non-specific changes in serum immunological parameters and that none of the observed changes were likely to be either causal or secondary to tropical sprue. The only exception to this was significantly elevated epithelial lymphocyte (EL) counts in the jejunal mucosal biopsies of the tropical sprue patients.

Increase in EL has been a consistent finding in all reports of jejunal mucosal pathology in this illness [41]. A detailed morphometric study of jejunal mucosal biopsies from chronic endemic tropical sprue patients in southern India [22] showed that increased EL in crypt epithelium, and increased immunoblasts and mitotic figures in EL, were significant, suggesting increased activity of these immunocytes. The EL were focally distributed in the upper crypt and crypt-villous interphase and were often adjacent to severely damaged enterocytes. In patients affected in an epidemic of tropical sprue, while enterocyte damage was visible at electron microscopic examination as early as $48 \mathrm{~h}$ from the onset of diarrhoea, EL changes were only detectable 3 weeks later. The presence of activated EL suggests a local cell-mediated immune reaction but the sequence of appearance of EL suggests that this is secondary to enterocyte damage.

There are some striking parallels between the histological appearance of the jejunal mucosa in tropical sprue and chronic graft-versus-host reaction (GVHD) [42] and a cytotoxic anti-epithelial cell antibody has been demonstrated in the serum of patients with chronic GVHD. In southern India, a similar antibody has been found in the serum of patients with chronic endemic tropical sprue. The significance of this antibody and its role in the pathogenesis of tropical sprue is not yet understood.

\section{Conclusions}

It is surprising that in the gastrointestinal tract, with a primary barrier function and a large population of immunocytes, a major role for immunological damage has been convincingly established only for a few diseases; pernicious anaemia, gluten-sensitive enteropathy and GVHD. The complexities in investigating this relatively inaccessible area and the necessity for studying appropriate controls by similar techniques are some of the reasons that explain this paucity of data.

Tropical sprue is a syndrome with an unusual geographical distribution and unknown aetiology. Alterations in gut immunocytes, especially EL, in this disease suggest that immune-mediated mechanisms may be important in the pathogenesis. However, the available data suggests that the initiating event leading to persistent damage to enterocytes in the stem cell compartment is unlikely to be immune mediated and that the immunological alterations are secondary to the loss of barrier function consequent to enterocyte damage.

\section{References}

1. Baker SJ, Mathan VI (1970) An epidemic of tropical sprue in southern India. II. Epidemiology. Ann Trop Med Parasitol 64: 453 
2. Baker SJ, Mathan VI (1971) Tropical sprue in south India. In: Tropical sprue and megaloblastic anaemia, Wellcome Trust Collaboartive Study. Wellcome Trust, Churchill Livingstone, Edinburgh, pp 189-260

3. Baker SJ, Mathan VI (1972) Tropical enteropathy and tropical sprue. Am J Clin Nutr 25: 1047

4. Baker SJ, Ignatius M, Mathan VI, Vaish SK, Chacko CJG (1962) Intestinal biopsy in tropical sprue. In: Wolstenholme GEW, Cameron MP (eds) Intestinal biopsy, Ciba Foundation Study Group No. 14. Churchill Livingstone, Edinburgh, pp 84-102

5. Baker SJ, Mathan M, Mathan VI, Jesudoss S, Swaminathan SP (1982) Chronic enterocyte infection with coronavirus. One possible cause of the syndrome of tropical sprue. Digest Dis Sci 27: 1039

6. Bhat P, Shanthakumari S, Rajan D, Mathan VI, Kapadia CR, Swarnabai C, Baker SJ (1972) Bacterial flora of the gastrointestinal tract in southern Indian control subjects and patients with tropical sprue. Gastroenterology 62: 11

7. Bhat P, Albert MJ, Rajan D, Ponniah J, Mathan VI, Baker SJ (1980) Bacterial flora of the jejunum: a comparison between luminal aspirate and mucosal biopsy. J Med Microbiol 13: 247

8. Chacko A, Begum A, Mathan VI (1984) Absorption of nutrient energy in southern Indian control subjects and patients with tropical sprue. J Clin Nutr 40: 771

9. Chacko CJG, Job CK, Johnson S, Baker SJ (1961) Histopathological changes in the upper jejunum in tropical malabsorption syndrome studied by transoral biopsy. Indian J Pathol Bacteriol 4: 203

10. Chacko CJG, Mathan VI, Baker SJ (1968) Changes in the mucosal pattern of isolated loops of jejunum in albino rats. Br J Exp Pathol 49: 40

11. Chacko CJG, Paulson KA, Mathan VI, Baker, SJ (1969) The villus architecture of the small intestine in the tropics: an autopsy study. J Pathol 98: 146

12. England, NWJ, O'Brien W (1966) Appearance of the jejunal mucosa in acute tropical sprue in Singapore. Gut 7: 128

13. Gorbach SL, Banwell JG, Jacob B, Chatterjee BD, Mitra R, Sen NN, Guha Mazumder DN (1970) Tropical sprue and malnutrition in West Bengal. 1. Intestinal microflora and absorption. J Clin Nutr 23: 1545

14. Klipstein FA (1971) Tropical sprue in the Western Hemisphere. In: Tropical sprue and megaloblastic anaemia, Wellcome Trust Collaborative study. Wellcome Trust, Churchill Livingstone, Edinburgh, pp 129-158

15. Klipstein FA, Baker SJ (1970) Regarding the definition of tropical sprue. Gastroenterology 58: 717

16. Klipstein FA, Corcino JJ (1974) Seasonal occurrence of overt and subclinical tropical malabsorption in Puerto Rico. J Am Trop Med Hyg 23: 1189

17. Klipstein FA, Falaiye JM (1969) Tropical sprue in expatriates from the tropics living in the continental United States. Medicine 48: 475

18. Klipstein FA, Holdeman LV, Corcino JJ, Moore, WEC (1973) Enterotoxigenic intestinal bacteria in tropical sprue. Ann Intern Med 79: 632

19. Klipstein FA, Engert RF, Short, HB (1978) Enterotoxigenicity of colonising coliform bacteria in tropical sprue and blind-loop syndrome. Lancet II: 342

20. Lindenbaum J (1968) Small intestine dysfunction in Pakistanis and American resident in Pakistan. Am J Clin Nutr 21: 1023

21. Lindenbaum J, Harmon JW, Gerson CS (1972) Subclinical malabsorption in developing countries. Am J Clin Nutr 25: 1056

22. Marsh MN, Mathan M, Mathan VI (1983) Studies of intestinal lymphoid tissue. VII. The secondary nature of lymphoid cell activation in the jejunal lesin of tropical sprue. Am J Pathol 112: 302

23. Mathan M, Mathan VI (1985) Rectal mucosal morphologic abnormalities in normal subjects in southern India. A tropical colonopathy. Gut 26: 710

24. Mathan M, Mathan VI, Baker SJ (1975) An electron microscopic study of jejunal mucosal morphology in control subjects and in patients with tropical sprue in southern India. Gastroenterology 68: 17

25. Mathan M, Mathan VI, Swaminathan SP, Yesudoss S, Baker SJ (1975) Pleomorphic virus-like particles in human faeces. Lancet I: 1068

26. Mathan M, Ponniah J, Mathan VI (1986) Epithelial cell renewal and turnover and its relationship to the morphological abnormalities in the jejunal mucosa in tropical sprue. Digest Dis Sci 31: 586

27. Mathan VI (1984) Tropical sprue. In: Bouchier IAD, Allan RN, Hodgson HJF, Keighly MRB (eds) Text book of gastroenterology, vol 1. Balliere Tindall, Eastbsourne, pp 471-479 
28. Mathan, VI (1987) The spectrum of gastrointestinal disease in India. In: Weatherall DJ, Lidinghan JGG, Warrel DA (eds) The Oxford text book of medicine. Oxford Med, pp 12, 278-12, 279

29. Mathan VI (1988) Tropical sprue in southern India. Trans Soc Trop Med Hyg 82: 10

30. Mathan VI, Baker SJ (1968) Epidemic of tropical sprue and other epidemics of diarrhoea in south Indian villages. Am J Clin Nutr 21: 1077

31. Mathan VI, Baker SJ (1970) An epidemic of tropical sprue in southern India. I. Clinical features. Ann Trop Med Parasitol 64: 439

32. Mathan VI, Baker SJ (1971) The epidemiology of tropical sprue. In Tropical sprue and megaloblastic anaemia, Wellcome Trust Collaborative study. Churchill Livingstone, London, pp $159-188$

33. Mathan VI, Mathan MM (1988) Viruses and tropical sprue, In: Farthing MJG, Keusch GT (eds) Enteric infection. Chapman and Hall Medical, London, pp 217-222

34. Mathan VI, Rajan DP (1986) The prevalence of bacterial enteric pathogens in a healthy population in southern India. $\mathrm{J}$ Med Microbiol 22: 93

35. Mathan VI, Joseph S, Baker SJ, (1969) Tropical sprue in children. Gastroenterology 56: 556

36. Mathan VI, Ponniah J, Mathan M (1982) Tropical enteropathy: an adaption of the small intestine to accelerated cell loss in "contaminated" environments. In: Robinson JWL, Dowling RH, Riecken EO (eds) MTP Press, Lancaster, pp 609-610

37. Miller DS, Rahman MA, Tanner R, Mathan VI, Baker SJ (1969) The vascular architecture of the different forms of small intestinal villi in the rat (Rattus norwegicus). Scand J Gastroenterol 4: 477

38. Ramakrishna BS, Mathan VI (1982) Water and electrolyte absorption by the colon in tropical sprue. Gut 23: 843

39. Ross IN, Mathan VI (1981) Immunological changes in tropical sprue. Q J Med 50: 435

40. Sheehy TW, Baggs B, Perez-Santiago E, Floch MH (1962) Prognosis of tropical sprue: a study of the effect of folic acid on the intestinal aspects of acute and chronic sprue. Ann Intern Med 57: 892

41. Swanson VL, Thomassen RW (1965) Pathology of the jejunal mucosa in tropical sprue. Am J Pathol 46: 511

42. Snover DC (1985) Weisder FSA, Vereelotti GM, Rank B, Huttan S, McGlove P (1985) A histopathological study of gastric and small intestinal graft versus host disease following allogenic bone marrow transplantation. Hum Pathol 16: 387

43. Wolf JL, Rubin DH, Finberg R, Kauffman RS, Sharpe AH, Trier JS (1981) Intestinal M. cells: a pathway for entry of reovirus into the host. Science $212: 471$ 